Revista Ibero-Americana de Ciências Ambientais

Ibero-American Journal of Environmental Sciences

Edição Especial do Congresso de Gestão Ambiental do Baixo Amazonas

(CONGABA) Ago 2018 - v.9 - n.6

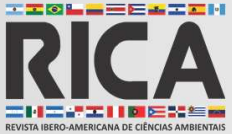

ISSN: 2179-6858

\title{
Produtividade de cultivares de soja associada a graus-dia acumulados sob condição agrometeorológicas em Belterra (PA)
}

A sojicultura vem crescendo em cultivos agrícolas, principalmente nas áreas que estavam com pecuária extensiva em vias de degradação na região Amazônica. A reintegração dessas áreas ao sistema produtivo tem proporcionado ganhos econômicos, inclusive associados aos ganhos educacionais, devida a consolidação de universidades no oeste do Pará, após assinatura da moratória da soja, ampliando-se a oferta de emprego com a instalação de novas empresas na região. Os agricultores têm buscado alternativas a fim de atenderem as demandas relacionadas ao fornecimento de sementes, adubos e, sobretudo, quanto ao aporte tecnológico, para garantir o processo produtivo, em cada ano, da safra de grãos. O objetivo neste trabalho foi avaliar a produtividade de cultivares de soja associadas à graus-dias acumulados para subsidiar estratégias quanto a época de semeadura em cultivos de soja sob condições agrometeorológicas em
Belterra (PA). Foram analisados dados de produtividades de diferentes cultivares com base em dados obtidos de experimento de campo em Belterra, onde foram fornecidas informações de Belterra (PA). Foram analisados dados de produtividades de diferentes cultivares com base em dados obtidos de experimento de campo em Belterra, onde foram fornecidas informações de
dias dos estádios fenológicos (germinação, floração e colheita). Dados meteorológicos diários foram tratados, sendo esses oriundos da estação do Instituto Nacional de Meteorologia (INMET). Em planilha eletrônica (Excel), foram realizados os cálculos de graus-dia acumulados, adotando a temperatura base da soja de $10^{\circ} \mathrm{C}$. O rendimento de grãos foi de $3,120 \mathrm{~kg}$.ha-1 na cultivar $\mathrm{B}$, e o mais elevado foi de 3,240kg.ha-1, na cultivar C. Ao avaliar os valores acumulados de graus-dia até a floração, a cultivar C obteve a maior soma térmica (574 ${ }^{\circ} \mathrm{C}$ ) e a cultivar B contabilizou os menores valores de $515,85^{\circ} \mathrm{C}$. A cultivar C, por ser de clico mais longo em relação as demais, contabilizou $1742^{\circ} \mathrm{C}$, refletindo nas maiores produtividades. $\mathrm{O}$ total de graus-dia para completar o ciclo na cultivar $C$ é indicativo de expressão em produtividade superior as demais cultivares analisadas, sendo uma variável resposta que deve ser considerada em planejamento de cultivos de soja para as condições de Belterra, importante município do polo de grãos do oeste do Pará.

Palavras-chave: Soma térmica; Fenologia; Glycine Max; Produtividade; Amazônia.

\section{Productivity of soybean cultivars associated with accumulated degree-days under agrometeorological condition in Belterra (PA)}

Soybean has been growing in agricultural crops, especially in areas that had extensive cattle ranching in degradation in the Amazon region. The reintegration of these areas into the productive

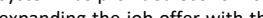
fertilizers and above all, regarding the technological input, to guarantee the production process, each year, of the grain harvest. The objective of this work was to evaluate the productivity of soybean cultivars associated with accumulated degree days to support strategies regarding sowing time in soybean crops under agrometeorological conditions in Belterra (PA). Productivity data from different cultivars were analyzed based on data obtained from field experiments in Belterra, where information was provided on days of phenological stages (germination, flowering and harvest). Daily weather data were processed, from the National Institute of Meteorology (INMET) station. In spreadsheet (Excel), the accumulated degree-day calculations were performed, adopting the soybean base temperature of $10^{\circ} \mathrm{C}$. The grain yield was $3,120 \mathrm{~kg}$.ha- 1 in cultivar $\mathrm{B}$, and the highest was $3,240 \mathrm{~kg}$.ha- 1 in cultivar $\mathrm{C}$. When evaluating the cumulative degree-day values until flowering, cultivar $\mathrm{C}$ obtained the highest thermal sum $\left(574^{\circ} \mathrm{C}\right)$ and cultivar B had the lowest values of $515.85^{\circ} \mathrm{C}$. The cultivar $\mathrm{C}$, being of longer cycle compared to the others, accounted for $1742^{\circ} \mathrm{C}$, reflecting in the highest yields. The total degree-days to complete the cycle in cultivar $\mathrm{C}$ is indicative of higher vield expression than the other cultivars analyzed, being a response variable that should be considered in soybean crop planning for Belterra conditions, an important municipality of grains of western Pará.

Keywords: Thermal sum; Phenology; Glycine Max; Productivity; Amazon.

Topic: Experimentação Agrícola

Reviewed anonymously in the process of blind peer
Received: 04/08/2018

Approved: 16/08/2018
Deyvielen Maria Ramos Alves

Universidade Federal do Oeste do Pará, Brasil

http://lattes.cnpq.br/6191998314534966

d.ellenalves@gmail.com

Lucieta Guerreiro Martorano (iD)

Embrapa Amazônia Oriental, Brasil http://lattes.cnpq.br/9712490260615310

http://orcid.org/0000-0003-3893-3781

lucieta.martorano@embrapa.br

José Reinaldo da Silva Cabral de Moraes (iD)

Instituto Federal de Educação, Ciência e Tecnologia de

Mato Grosso do Sul, Brasil

http://lattes.cnpq.br/2670721926559119

http://orcid.org/0000-0002-8567-4893

reinaldojmoraes@gmail.com
Werlleson Nascimento

Universidade Federal do Oeste do Pará, Brasi http://lattes.cnpq.br/7637439330380174 werlleson.nascimento@gmail.com

Lucas Eduardo de Oliveira Aparecido (iD

Instituto Federal de Educação, Ciência e Tecnologia de Mato Grosso do Sul, Brasil

http://lattes.cnpq.br/1805687336632729

http://orcid.org/0000-0002-4561-6760

lucasedap.bol@hotmail.com

Kelly Karoline de Souza Mello

Universidade Federal do Oeste do Pará, Brasil

http://lattes.cnpq.br/3680352705883848

kellykarolinemello@gmail.com
Eudilene Dalet Vitor de Sousa

Universidade Federal do Oeste do Pará, Brasil http://lattes.cnpq.br/1210121065910515 daletvitor@gmail.com
6

DOI: 10.6008/CBPC2179-6858.2018.006.0006
Referencing this:

ALVES, D. M. R.; MARTORANO, L. G.; MORAES, J. R. S. C.; NASCIMENTO, W.; APARECIDO, L. E. O.; MELLO, K. K. S.; SOUSA, E. D. V.. Produtividade de cultivares de soja associada a graus-dia acumulados sob condição agrometeorológicas em Belterra (PA). Revista Ibero-Americana de Ciências Ambientais, v.9, n.6, p.46-53, 2018. DOI: http://doi.org/10.6008/CBPC2179-6858.2018.006.0006 


\section{INTRODUÇÃO}

A oferta de alimentos oriunda da cadeia produtiva de grãos tem ampliado o interesse dos produtores no oeste do Pará, pincipalmente pela facilidade de escoamento da produção no Porto de Santarém aos mercados nacionais e internacionais. Três fatores podem ser apontados como expressivos após a instalação de polos agrícolas em desenvolvimento: crescimento populacional, migração da área rural para o meio urbano e aumento da renda per capita. Segundo dados do Ministério da Agricultura, em 2012, o PIB do agronegócio brasileiro foi de $\mathrm{R} \$ 386 \mathrm{bi}$, representando, aproximadamente, 30\% do PIB nacional (FRANCO, 2014).

Os líderes mundiais na produção de soja, atualmente, são Estados Unidos, Brasil, Argentina, China, Índia e Paraguai, respectivamente. A soja é um dos principais itens na lista de exportações no Brasil. Vale destacar que em 2013 as exportações foram da ordem de 26 milhões de toneladas de grãos, 5,3 milhões de farelo de soja e 579.690 toneladas de óleo de soja (bruto e refinado), totalizando $25,75 \%$ das exportações brasileiras, conforme dados da Companhia Nacional do Abastecimento (CONAB, 2016). O cultivo da soja (Glycine max L.) representa relevância econômica, ganhando cada vez mais espaço em diferentes setores, dentre eles nas indústrias de alimentos como matéria-prima. O Brasil, em decorrência da vasta área cultivada com essa cultura, vem crescendo no mercado de exportações, inclusive agregando alto aporte financeiro pela sojicultura (PEREIRA et al., 2017).

Condições climáticas e de relevo foram apontadas como favoráveis aos cultivos de soja no Bioma Cerrado (EMBRAPA, 2000), expandindo-se as áreas para as regiões mais ao norte do Brasil. O estado do Pará possui municípios com maior crescimento em lavoura com soja, como por exemplo, Paragominas, Dom Eliseu, Ulianópolis e Rondon do Pará. Ressalta-se que os municípios de Redenção, Conceição do Araguaia, Cumaru do Norte, Santana do Araguaia e Santa Maria das Barreiras tiveram um aumento de mais 200 vezes, passando de 500 hectares em 2002 para 110 mil hectares em 2014 (ARAÚJO et al., 2017).

Cultivos de soja em sistemas de produção não irrigados apresentam alta dependência quanto ao regime pluvial de uma determinada região, para garantir os estoques de água no solo para atender as demandas hídricas da cultura, principalmente nos estádios fenológicos mais sensíveis como na germinação e floração (MARTORANO et al., 2012). Todavia, existem outros fatores que também podem ser limitantes, como a fertilidade do solo, radiação solar, temperatura, vento e capacidade de resistência de cultivar em períodos de déficits hídricos (MARTORANO et al., 2009).

Sempre que novas cultivares são lançadas no mercado, recomendam-se avaliações e condições edafoclimáticas capazes de explicar efeitos quanto ao crescimento, desenvolvimento e produtividade e, consequentemente, o desempenho agronômico de cada material comercializado (ROSA et al., 2009). Além da oferta pluvial, é necessário avaliar outras variáveis agrometeorológicas como fotoperíodo, temperatura e radiação solar favoráveis aos processos fisiológicos e produtividade potencial das cultivares bem como o sistema de manejo do solo (CORREA et al., 2011). Em se tratando de disponibilidade hídrica à planta, o estresse de água no solo desencadeia alterações em níveis metabólicos e morfológicos, os quais podem 
promover ajuste da planta sob condições adversas, proporcionando a continuidade do desenvolvimento da soja para manter o seu potencial produtivo (FERRARI et al., 2015).

Estudos com base na soma térmica têm auxiliado nas análises dos efeitos da temperatura do ar no crescimento e desenvolvimento das plantas (PAULA et al., 2015). Cálculos de graus-dia acumulados auxiliam na escolha de material genético compatível com regime térmico local. De acordo com Melo et al. (2006) essas estimativas subsidiam a definição de épocas semeadura, planejamento no período de colheita, épocas de maior vulnerabilidade à ocorrência de pragas e doenças e, sobretudo, nas estimativas de produtividade em anos-safra. Conhecer a época de ocorrência de subperíodos críticos, a determinados estresses abióticos à planta, ou seja, baixas ou altas temperaturas, são de extrema importância para diminuir ou aumentar efeitos termorreguladores (STEINMETZ et al., 2017) capazes de comprometer a produção de grãos (FERNEDA et al., 2016).

Na literatura, são encontrados vários trabalhos sobre o índice térmico, como a determinação do ciclo de cultivos (AJAYI et al., 2004; APARECIDO et al., 2014), a distribuição de espécies em cenários climáticos futuros (FRANKLIN et al., 2012), em técnicas de modelagem para estimativa de produtividade de grãos (ROBERTS et al., 2012), extrapolar a transpiração do cultivo de Videiras (LÓPEZ-URREA et al., 2012), além de estimativas da época da maturação de frutos (BARDIN-CAMPAROTTO et al., 2012). Nesse contexto, o objetivo neste trabalho foi avaliar a produtividade de cultivares de soja associadas aos graus-dias acumulados para subsidiar estratégias quanto a época de semeadura em cultivos de soja sob condições agrometeorológicas em Belterra (PA).

\section{METODOLOGIA}

Os dados foram oriundos de experimento em campo onde foram extraídas informações capazes de expressar os estádios fenológicos de cultivares de soja, considerando-se o período entre o final de dezembro de 2016 e início de maio de 2017, divergindo entre as cultivares. Entre o dia 26, de dezembro de 2016 e os dias 04 e 16 de janeiro de 2017 ocorreram às semeaduras das variedades: A (Biogene 4184), B (Pioneer 98y52), C (TMG 1288 RR), respectivamente. Estas tiveram sua floração nos dias 01, 09 e 26 de fevereiro de 2017, e a colheita de A e B ocorreu nos dias 05 e 23 de abril, bem como no dia 09 de maio da cultivar C.

Os estádios fenológicos da soja avaliados ao logo das atividades de campo foram estabelecidos segundo a escala de Fehr et al. (1977). As anotações nas cadernetas dos técnicos de campo permitiram a extração de informações capazes de identificar se as anotações continham anotações referentes aos estádios fenológicos de cada cultivar. Foram contabilizados os valores de chuva, a partir da data de semeadura. Assim, da emergência até a floração foram analisadas as variáveis térmicas e hídricas, em Belterra, no estado do Pará.

Dados de temperatura do ar foram contabilizados, considerando-se a escala temporal diária, com base aos dados obtidos na base do Instituto Nacional de Meteorologia (INMET), coletados na estação meteorológica de Belterra, município onde também os dados experimentais foram obtidos, sendo esse localizado na região Oeste do Pará. Estes dados coletados foram analisados e tratados, contabilizando-se as 
somas térmicas a partir da data de germinação. Foram avaliados do dia de semeadura, floração e colheita, da cultura da soja.

Utilizaram-se planilhas no Microsoft Excel para a construção de gráficos, onde se calculou o ciclo fenológico em graus-dia acumulados, usando a temperatura base para a soja de $10^{\circ} \mathrm{C}$. Para o cálculo dos graus-dia, utilizou-se o método da menor variabilidade, proposto por Arnold (1960) e utilizado por Brunini et al. (1976) e Berlato et al. (1978). Este método consiste em se determinar o total de somas térmicas contabilizadas ao longo do ciclo de uma cultura, utilizando-se a equação $G D=\sum_{i=1}^{n}(T i-T b)$, em que GD corresponde aos graus-dia acumulados no período; Ti trata-se da temperatura média diária $\left({ }^{\circ} \mathrm{C}\right) ; \mathrm{Tb}$ corresponde ao valor considerado para a temperatura base, neste trabalho foi $10^{\circ} \mathrm{C}$; e ' $n$ ' representa o número de dias correspondentes ao período considerado.

Como temperatura máxima, foram computadas as temperaturas menores ou iguais a $30^{\circ} \mathrm{C}$; como temperatura mínima, foram consideradas temperaturas maiores ou iguais a $10^{\circ} \mathrm{C}$ e como temperatura base (Tb), Foi Utilizada a temperatura de $10^{\circ} \mathrm{C}$ (BRUNINI et al., 1976; BERLATO et al., 1979; CARDOSO et al., 1979). As plantas necessitam acumular graus-dia durante o seu desenvolvimento para completarem o seu ciclo de vida. Cada cultura possui faixas térmicas que podem ser ótimas e limitantes ao seu desenvolvimento. Esses limiares variam de acordo com as espécies de planta. A título de estimativa adota-se a temperatura-base como condição limitante ao estresse por frio em culturas adaptadas a regiões de clima tropical (CAMARGO et al., 1987).

\section{RESULTADOS}

As cultivares avaliadas possuem rendimentos que variaram entre $3,120 \mathrm{~kg}^{-h^{-1}}$ (cultivar B) com menor rendimento de grãos a 3,240kg. ha-1 (cultivar C), com maiores rendimentos de grãos. Ao avaliar os valores acumulados de graus-dia até a floração, a cultivar C obteve a maior soma térmica com $574^{\circ} \mathrm{C}$ e a cultivar B menor soma térmica contabilizando $515,85^{\circ} \mathrm{C}$. Os valores de graus-dia acumulados até a colheita, que corresponde desde a fase de emergência até a maturação, diferem-se entre as cultivares em comparação a floração, pois a cultivar $\mathrm{A}$, apresentou a menor soma térmica com $1522^{\circ} \mathrm{C}$. A cultivar $\mathrm{C}$ até a floração contabilizou $1742^{\circ} \mathrm{C}$, refletindo nas maiores produtividades (figura 1 ).

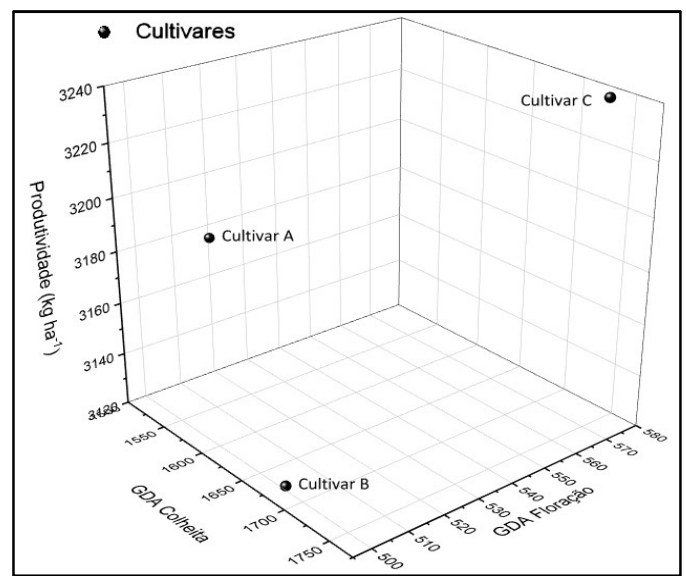

Figura 1: Produtividade comparada aos graus-dia acumulados entre emergência a floração e até a colheita de grãos de cada cultivar (A, B e C). 
As cultivares ( $A, B$ e $C$ ) analisadas completaram seu ciclo produtivo sob condições térmicas médias em torno de $25,5^{\circ} \mathrm{C}$, indicando que a temperatura do ar é o elemento meteorológico que apresenta baixa variabilidade na região (MARTORANO et al., 1992). Observa-se que as cultivares até o período de floração receberam as maiores cotas de águas pluviais (figura 2 ).

Vale ressaltar que, de acordo com Martorano et al. (2009), períodos longos de escassez de água no solo limitam a expressão do potencial em rendimento de grãos da soja, principalmente no período de germinação e floração. Ao avaliar a cultivar $\mathrm{C}$ que foi a mais produtiva, verificou-se que ao atingir o estádio $R_{1}$ (floração) com 34 dias após a emergência (DAE) foram contabilizados $407 \mathrm{~mm}$. Esses aportes de água refletem efeitos positivos ao acúmulo de fotoassimilados e, consequentemente explicando os maiores rendimentos de grãos dessa cultivar.

A precocidade observada na cultivar A, completando seu ciclo aos $95 \mathrm{DAE}$, destaca que até a floração choveu $266 \mathrm{~mm}$, indicando reduções na oferta pluvial ao comparar com o volume contabilizado até a floração da cultivar C. Nota-se que também os valores foram superiores aqueles até a floração da cultivar B. Nos primeiros 15 dias de cada cultivar, considerando-se a data em que as cultivares foram semeadas a campo, é possível notar que as chuvas ficaram abaixo de $15 \mathrm{~mm}$ para a cultivar $\mathrm{A}$, muito diferente do que ocorreu, nesse mesmo período de tempo quando avalia-se as condições pluviais para a cultivar $\mathrm{C}$. As chuvas foram bem distribuídas até a floração para a cultivar $C$, fato esse que pode explicar os valores obtidos em rendimento de grãos dessa cultivar, quando comparada às demais.

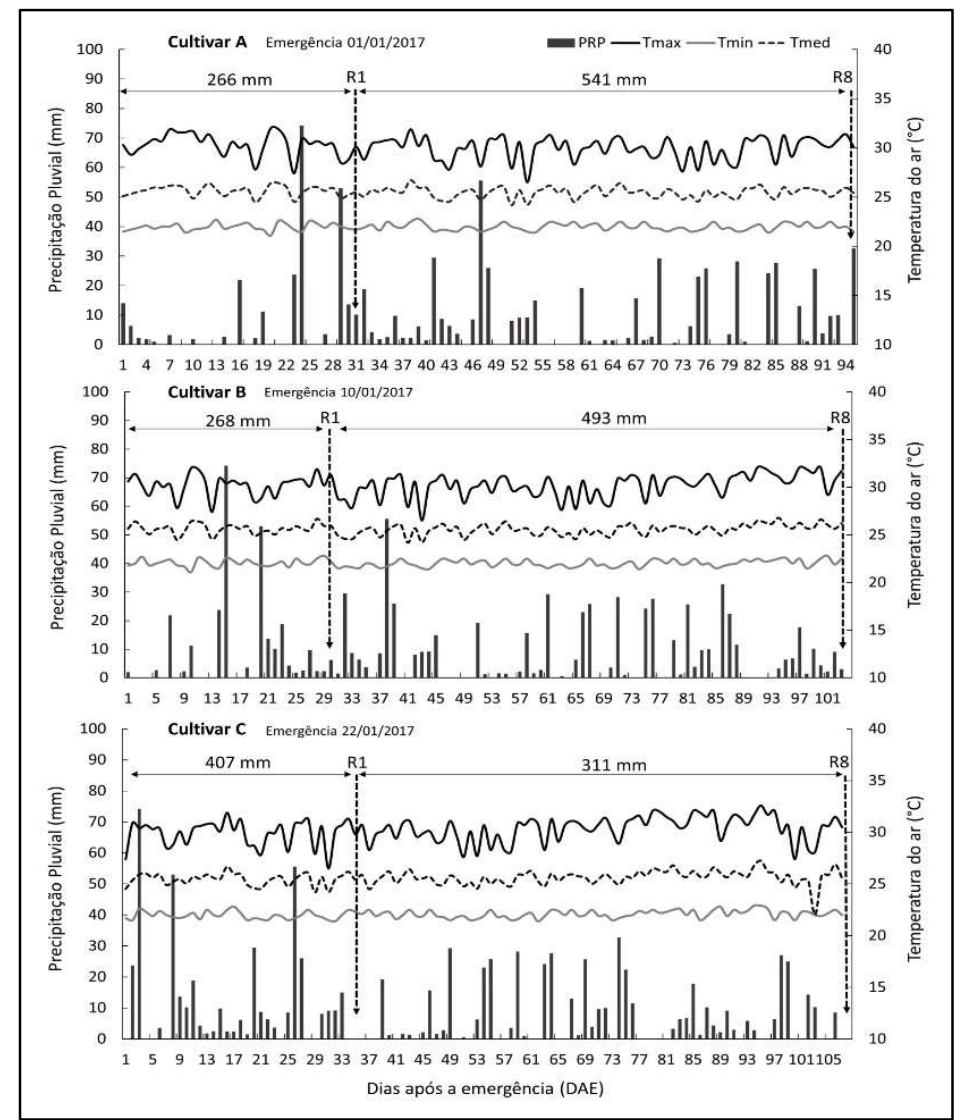

Figura 2: Variabilidade da Precipitação Pluvial (PRP), Temperatura máxima (Tmax), Temperatura mínima (Tmin) e Temperatura média (Tmed) entre as cultivares $A$, B e C. 
As especificações da cultivar $C$ apontam com excelente arquitetura, facilitando o manejo e a penetração de luz para as folhas mais próximas ao solo, indicando que essa característica amplia a eficiência fotossintética, não limitando apenas as folhas que compõe o dossel dessa cultivar. Sendo a cultivar C com o ciclo mais logo em relação aos outros materiais analisados neste trabalho e sistema radicular profundo, essa produtividade pode também ser explicada pelo fato das raízes conseguirem explorar camadas mais profundas do solo, ampliando-se a capacidade de extração de água em eventuais períodos de veranicos, durante o seu ciclo vegetativo da cultivar.

Cada cultivar necessita de um determinado acúmulo energia como, por exemplo, expresso pelo índice fototérmico até atingir um determinado estádio reprodutivo, sendo seu período de duração de dia ótimo, crítico ou restrito seja variável, de acordo com o material genético associado às condições climáticas de um local (DALLACORT et al., 2006).

\section{DISCUSSÃO}

Vale reforçar que a decisão do produtor quanto a data da semeadura demanda de informações agrometeorológicas para subsidiar o planejamento em anos safra. Considerando-se que a data da emergência da cultivar A ocorreu em 01/01/2017, os valores de chuva até a floração foram inferiores aos observados para as cultivares B e C, possivelmente porque os efeitos decorrentes da presença da Zona de Convergência Intertropical (ZCIT), ainda não estavam garantindo a oferta pluvial, típica do período chuvoso na região.

Dez dias depois quando a cultivar B estava no seu estádio de emergência, nota-se que o volume de água precipitado até a floração atingiu 268mm. Aos 22 dias do mês de janeiro de 2017, os valores pluviais já evidenciavam maior oferta de chuva, o que permitiu que a cultivar $C$ recebesse até a floração valores mais expressos em termos de volume de chuva.

Ferneda et al. (2016) analisou quatro cultivares, duas transgênicas e duas convencionais, que possuem ciclo indeterminado, nas quais a temperatura afetou diretamente o crescimento da soja. Temperaturas acima de $40^{\circ} \mathrm{C}$ reduzem os rendimentos de grãos. Ferneda et al. (2016) destacou que a temperaturas do ar quando estão abaixo de $10^{\circ} \mathrm{C}$, comprometem a expressão da planta em produtividade. As temperaturas decresceram ao final de outubro, apresentando velocidades de crescimento diferentes para as épocas de semeadura.

Souza et al. (2010), avaliando o albedo da soja plantada em condições naturais de campo, em Paragominas, PA e parâmetros biofísicos como índice de área foliar, observou valores de graus-dia acumulados de $1297,62^{\circ} \mathrm{C}$. Os referidos autores identificaram no caso do albedo o período mais crítico para a cultura é no estádio fenológico de frutificação.

\section{CONCLUSÕES}

O total de graus-dia para completar o ciclo na cultivar C é indicativo de expressão em produtividade superior as demais cultivares analisadas, sendo uma variável resposta que deve ser considerada em 
planejamento de cultivos de soja para as condições de Belterra, importante município do polo de grãos do oeste do Pará.

\section{REFERÊNCIAS}

AJAYI, A. E.; OLUFAYO, A. A.. Evaluation of two temperature stress indices to estimate grain sorghum yield and evapotranspiration. Agronomy Journal, Madison, n.96, p.1282-1287, 2004

APARECIDO, L. E. O.; ROLIM, G. S.; SOUZA, P. S.. Épocas de florescimento e colheita da nogueira-macadâmia para áreas cafeícolas da região sudeste. Revista Brasileira de Fruticultura, v.36, n.1, 2014.

ARNOLD, C. Y.. Maximum-minimum temperatures as a basis for computing heat units. American Society for Horticultural Science, Boston, v.76, p.682-692, 1960.

BARDIN-CAMPAROTTO, L.; CAMARGO, M. B. P.; MORAES, J. F. L.. Estimated time of grain ripening of different arabica coffee cultivars for the São Paulo State, Brazil. Ciência Rural, Santa Maria, v.42, n.4, p.594-599, 2012.

BERLATO, M. A.; MATZENAUER, R.; SUTILI, V. R.. Relação entre temperatura e desenvolvimento do milho. In: REUNIÃO BRASILEIRA DE MILHO E SORGO, 12. Anais. Brasília: EMBRAPA, 1978.

BRUNINI, O.; LISBÃO, R. S.; PEDRO JÚNIOR, M. J.. Temperatura-base para alface cultivar 'White Boston' em um sistema de unidades térmicas. Bragantia, v.35, n.19, p.213-219, 1976.

CAMARGO, M. B. P.; BRUNINI, O.; MIRANDA, M. A. C. Temperatura-base para cálculo dos graus-dia para cultivares de soja em São Paulo. Pesquisa Agropecuária Brasileira, Brasília, v.22 n.2, p.115-121, 1987.

CARDOSO, M. J.; MUNDSTOCK, C. M.. Comparação de treze métodos de cálculo de unidades Otérmicas de desenvolvimento de milho (Zea mays L.). Ciência e Cultura, São Paulo, v.31, n.11, p.1278-1283, 1979.

CONAB. Companhia Nacional de Abastecimento. Acompanhamento da safra brasileira de grãos: Safra 2015/16. Brasília: CONAB, 2016.

CORREA, S. T. R.; DOURADO NETO, D.; LORENÇONI, R.; SCARPARE, F. V.; VIVIAN, R.; RUIZ, E. T.. Aplicações e limitações da modelagem em agricultura: revisão. Revista de Agricultura, Piracicaba, v.86, n.1, p.1-13, 2011.

DALLACORT, R.; FREITAS, P. S. L.; FARIA, R. T.; GONSALVES, A. C. A.; REZENDE R.; BERTONHA, A.. Utilização do modelo cropgro-soybean na determinação das melhores épocas de semeadura da cultura da soja, na região de Palotina, estado do Paraná. Acta Scientiarum, v.28, n.4, p.583-589, 2006.

EMBRAPA. Empresa Brasileira de Pesquisa Agropecuária. Tecnologias de produção da soja. Paraná: Embrapa, 2000.

FEHR, W. R.; CAVINESS, C. E.. Stages of soybean

development. Ames: lowa State University, 1977.
FERNEDA, B. G.; BOEING, E.; SILVA, A. C.; MARTIM, C. C.; PALADINO, F. G.; TANAKA, A. A.. Graus-dias na estimativa das taxas de crescimento de quatro cultivares de soja em diferentes épocas de plantio. Nativa, Sinop, v.4, n.3, p.121127, 2016. DOI: http://doi.org/10.14583/23187670.v04n03a01

FERRARI, E.; PAZ, A.; SILVA, A. C.. Déficit hídrico no metabolismo da soja em semeaduras antecipadas no Mato Grosso. Nativa, Sinop, v.3, n.1, p.67-77, 2015. DOI: http://doi.org/10.14583/2318-7670.v03n01a12

FRANCO, C.. Fatores produtivos e inter-relações na produção da soja em mato grosso. Revista Presença Geográfica, v.1, n.1, 2014.

FRANKLIN, J.; DAVIS, F. W.; IKEGAMI, M.; SYPHARD, A. D.; FLINT, L. E.; FLINT, A. L.; HANNAH, L.. Modeling plant species distributions under future climates: how fine scale do climate projections need to be?. Global Change Biology, Oxford, v.19, n.2, p.473-483, 2012.

MARTORANO, L. G., BERGAMASCHI, H.; FARIA, R. T.; DALMAGO, G. A.. Decision strategies for soil water estimations in soybean crops subjected to no-tillage and conventional systems, in Brazil. Passo Fundo: Intechopen, 2012.

MARTORANO, L. G.; BERGAMASCHI, H.; DALMAGO, G. A.; FARIA R. T.; MIELNICZUK, J.; COMIRAN, F.. Indicadores da condição hídrica do solo com soja em plantio direto e preparo convencional. Revista Brasileira de Engenharia Agrícola e Ambiental, Campina Grande, v.13, n.4, p.397405, 2009.

MARTORANO, L. G.; PEREIRA, L. C.; COSTA, A. C. L.; RIBEIRO, J. T.. Variabilidade da Precipitação Pluviométrica em BelémPará Associada ao Fenômeno El Nino. In: CONGRESSO BRASILEIRO DE METEOROLOGIA, 7. Anais. São Paulo: SBM, 1992.

MELO, L. A. M. P.; TENENTE, R. C. V.; OLIVEIRA, M. R. V.. Cálculo de graus-dia acumulados para subsidiar ações de gerenciamento de risco de pragas. Brasília: 2006.

PAULA, F. L. M.; STRECK, N. A.; HELDWEIN, A. B.; BISOGNIN, D. A.; PAULA, A. L.; DELLAI, J.. Soma térmica de algumas fases do ciclo de desenvolvimento da batata (Solanum tuberosum L.). Ciência Rural, v.35, n.5. 2005.

PEREIRA, G.; NASCIMENTO, N.. Cenário das exportações brasileiras de SOJA: uma análise do mercado chinês. Caderno Científico, v.1, p.1-10, 2017.

ROBERTS, M. J.; SCHLENKER, W.; EYER, J.. Agronomic Weather Measures in Econometric Models of Crop Yield with Implications for Climate Change. American Journal of Agricultural Economics, Saint Paul, v.95, n.2, p.236-243, 2012. 
ROSA, H. T.; WALTER, L. C.; STRECK, N. A.; ALBERTO, C. M.. Métodos de soma térmica e datas de semeadura na determinação de filocrono de cultivares de trigo. Pesquisa Agropecuária Brasileira, Brasília, v.44, n.11, p.1374-1382, 2009.

SOUZA, P. J. P. P.; RIBEIRO, A.; ROCHA, E. J. P.; LOUREIRO, R. S.; BISPO, C. J. C.; SOUSA, A. M. L.. Albedo da cultura da soja em área de avanço da fronteira agrícola na Amazônia.
Revista Brasileira de Engenharia Agrícola e Ambiental, v.14, n.1, p.65-73, 2010.

STEINMETZ, S.; CUADRA, S. V.; ALMEIDA, I. R.; JUNIORMAGALHÃES, A. M.; FAGUNDES, P. R. R.. Soma térmica e estádios de desenvolvimento da planta de grupos de cultivares de arroz irrigado. Revista da Sociedade Brasileira de Agrometeorologia, Passo Fundo, v.25, n.2, p.405-414, 2017.

A CBPC - Companhia Brasileira de Produção Científica (CNPJ: 11.221.422/0001-03) detém os direitos materiais desta publicação. Os direitos referem-se à publicação do trabalho em qualquer parte do mundo, incluindo os direitos às renovações, expansões e disseminações da contribuição, bem como outros direitos subsidiários. Todos os trabalhos publicados eletronicamente poderão posteriormente ser publicados em coletâneas impressas sob coordenação da Sustenere Publishing, da Companhia Brasileira de Produção Científica e seus parceiros autorizados. Os (as) autores (as) preservam os direitos autorais, mas não têm permissão para a publicação da contribuição em outro meio, impresso ou digital, em português ou em tradução. 